Geluykens R (1994). The pragmatics of discourse anaphora in English: evidence from conversational repair. Berlin: Mouton de Gruyter.

Himmelmann N P (1996). 'Demonstratives in narrative discourse: a taxonomy of universal uses.' In Fox B A (ed.) Studies in anaphora. Amsterdam/Philadelphia: John Benjamins. 206-254.

Huang Y (2000). Anaphora. A cross-linguistic study. Oxford: Oxford University Press.

Kleiber G (1994). Anaphores et pronoms. Louvain-laNeuve: Duculot.

Langacker R W (1996). 'Conceptual grouping and pronominal anaphora.' In Fox B A (ed.) Studies in anaphora. Amsterdam/Philadelphia: John Benjamins. 333-378.
Levinson S C (1995). 'Three levels of meaning.' In Palmer F (ed.) Grammar and meaning. Essays in honour of Sir John Lyons. Cambridge: Cambridge University Press. 90-115.

Lyons J (1977). 'Deixis, space and time.' In Semantics (Ch. 15), vol. 2. Cambridge: Cambridge University Press. 636-724.

van Hoek K (1997). Anaphora and conceptual structure. Chicago: University of Chicago Press.

Yule G (1981). 'New, current and displaced entity reference.' Lingua 55, 41-52.

Ziv Y (1996). 'Pronominal reference to inferred antecedents.' Belgian Journal of Linguistics 10, 55-67.

\title{
Discourse Domain
}

P A M Seuren, Max Planck Institute for Psycholinguistics, Nijmegen, The Netherlands

(c) 2006 Elsevier Ltd. All rights reserved.

A discourse domain $\mathbf{D}$ is a cognitive space for the middle-term storage of the information conveyed by subsequent utterances. The notion of discourse domain is part of the theory of discourse semantics, which holds that the interpretation of utterances is codetermined by the information stored in the $\mathrm{D}$ at hand. For an utterance $u$ to be interpretable, $u$ must be anchored in a given $\mathrm{D}$. The anchoring of $u$ requires, at least, that all referring expressions in $u$, including anaphoric pronouns, link up with an address in $\mathrm{D}$ that represents the object or objects referred to. The information conveyed by the main predicate in the sentence $S$ underlying $u$ is then distributed over the relevant addresses. This process is called the incrementation of $S$ or i(S). When $S$ presupposes $P, P$ must be incremented before $S$. When $\mathrm{D}$ does not yet contain $\mathrm{i}(\mathrm{P}), \mathrm{i}(\mathrm{P})$ is supplied post hoc by accommodation (see Presupposition), unless blocked. Ds are subject to a condition of consistency and a condition of cognitive support, ensuring the compatibility of accommodated increments with available world knowledge, unless $\mathrm{D}$ specifies otherwise.

A D contains object addresses, domain addresses, and instructions. Object addresses represent real or fictitious objects. A (singular or plural) object address is created, in principle, by an existentially quantified sentence, say, There is a king, resulting in a labeled address (where $\mathbf{n}$ is an arbitrary natural number):

\section{(1) d-n [a | King(a)]}

or 'there is an a such that a is a king' (disregarding tense). The sentence $\mathrm{He}$ is rich results in:

\section{(2) d-n [a | King(a) // Rich(n)]}

or ' $\mathbf{n}$ is rich,' where $\mathbf{n}$ stands for 'the a such that a is a king.' In (1), a is an existential quantifier; in (2), $\mathbf{a}$ is a definite determiner - a function from the predicate extension [[King]] to an object (the reference value). The change is due to address closure, represented as //, which takes place when an open address is called on by a subsequent definite term. Address closure enables the semantic distinction between the open address in (3a) and the closed address in $(3 b)$ :

(3a) John has few clients who are dissatisfied. (open address)

(3b) John has few clients. And they are dissatisfied. (closed address)

Some addresses are subdomains, representing what has been specified as someone's belief (hope, knowledge, etc.), as being possible or necessary, or the alternatives of an or-disjunction. There is an intricate system of interaction between the main $\mathrm{D}_{\mathrm{o}}$ and subdomains $\mathbf{D}_{s}$. Information within $\mathbf{D}_{\mathrm{o}}$ can be called on in any $\mathbf{D}_{s}$, unless blocked by contrary information in $D_{s}$ (downward percolation). Likewise, unless blocked in $D_{o}$, presuppositions accommodated in a $D_{s}$ are also accommodated in $\mathbf{D}_{\mathbf{o}}$ (projection).

A D may also contain instructions constraining its further development. Negation, as in not- $S$, is an instruction banning $i(S)$ from $D$. This explains the incoherence of example (4), where the pronoun it calls on an address that has just been banned:

(4) !John has no car. It is in the garage.

The study of discourse domains is still in its infancy. Yet it already provides explanations for phenomena that have so far remained obscure. 
See also: Anaphora, Cataphora, Exophora, Logophoricity; Definite and Indefinite; Denotation versus Connotation; Discourse Semantics; Donkey Sentences; Presupposition; Projection Problem.

\section{Bibliography}

Seuren P A M (1985). Discourse semantics. Oxford: Blackwell.

\section{Discourse Markers}

J R Trillo, Universidad Autónoma de Madrid, Madrid, Spain

(c) 2006 Elsevier Ltd. All rights reserved.

Discourse markers can be defined as those elements, such as you know, I mean, well, oh, m, you see, look, listen, that have a distinct prosodic entity, tend not to have a specific semantic meaning, and contribute to scaffold the pragmatic coherence of interaction (see Scaffolding in Classroom Discourse). Broadly speaking, discourse markers have often been described by their absence of traditional linguistic properties, since neither their use nor their meaning seem to resemble any of the traditional linguistic categories. In fact, these elements have been typically discarded from rigorous linguistic studies, and in different languages have been assigned the general vague name of 'particelle' (Italian), 'fillers' (English), or 'muletillas' (Spanish) - both the English and the Spanish terms evidence these markers' function of 'filling' or 'supporting' discourse. In some sociolinguistic domains, discourse markers were marginalized because they were traditionally attributed to incompetent and incoherent speakers of a language (Watts, 1989).

Schenkein (1972) and Jefferson (1978) were among the first that became convinced of the need to study these vague elements that seem to distort syntax and have a multiplicity of undefined meanings. As an instance, consider how Dik (1989: 45) characterized these elements as 'extra-clausal constituents'; their role in natural language was described as follows: "any natural language text can be exhaustively divided into clauses and extra-clausal constituents ... which are neither clauses nor part of clauses." In other words, discourse markers, for this author, belong to the realm of spoken language and need to be studied only with reference to the parameters of spoken language.

In the 1980s and early 1990s, some authors studied the general presence of discourse markers in several languages, with no special reference to any grammatical or syntactic model. Thus, for instance, Vicher and Sankoff (1989) described discourse markers in contemporary French; Bazzanella (1990) did the same for contemporary Italian, and Fraser-Gupta (1992) for Singapore colloquial English. Other studies delved into the use of a specific discourse marker in a language, giving a full description of its different functions; cf., for example, Tognini-Bonelli (1993) on 'actually' in British English.

Since then, several authors have tried to name, classify, and describe the nature and function of these seemingly 'elusive' elements. In my opinion, there are three main approaches to the study of discourse markers: the conversational, the grammaticosyntactic, and the discourse-cognitive.

The conversational approach concentrates on the role of discourse markers in the structure of conversation. For example, Schegloff (1984), who called them "continuers," stated that they are used by the speaker to show the listener that his/her speech forms a coherent whole in progress. In the same vein, Schiffrin (1987: 31) provides the following definition: "markers are sequentially dependent elements that bracket units of talk." Both authors (along with others) agreed on the essentially spoken nature of these elements; from their studies, one is led to conclude that discourse markers are better analyzed from an interactional than from an ideational perspective (following Halliday's (1994) macrofunctions of language) (see Systemic Theory). In fact, Schiffrin (1985: 281) pointed out that: "discourse markers ... help speakers express interactional alignments toward each other and enact conversational moves"; elsewhere she stated (Schiffrin, 1987) that the presence of discourse markers in a conversation helps the mechanics of turn-taking, the organization of speech acts, the structuring of discourse ideas, the interactive structure of participants, and the presentation of information.

The second model corresponds to the grammaticosyntactic approach to discourse markers. Among others, Knott and Dale (1994: 45) described discourse markers as a "reasonably homogeneous group" that tends to be formed by "simple linguistic expressions [their italics] ... that have become simplified because they correspond to constructs that are in continual use when we process text." In their description of 